\title{
Mapping ecosystem functions to the valuation of ecosystem services: implications of species-habitat associations for coastal land-use decisions
}

\author{
James N. Sanchirico $\cdot$ Peter Mumby
}

Received: 28 July 2008 / Accepted: 28 November 2008 / Published online: 8 January 2009

(C) The Author(s) 2008. This article is published with open access at Springerlink.com

\begin{abstract}
Habitats and the ecosystem services they provide are part of the world's portfolio of natural capital assets. Like many components of this portfolio, it is difficult to assess the full economic value of these services, which tends to over-emphasize the value of extractive activities such as coastal development. Building on recent ecological studies of species-habitat linkages, we use a bioeconomic model to value multiple types of habitats as natural capital, using mangroves, sea grass, and coral reefs as our model system. We show how key ecological variables and processes, including obligate and facultative behaviors map into habitat values and how the valuation of these ecological processes can inform decisions regarding coastal development (habitat clearing). Our stylized modeling framework also provides a clear and concise road map for researchers interested in understanding how to make the link between ecosystem function, ecosystem service, and conservation policy decisions. Our findings also highlight the importance of additional ecological research into how
\end{abstract}

Electronic supplementary material The online version of this article (doi:10.1007/s12080-008-0034-0) contains supplementary material, which is available to authorized users.

J. N. Sanchirico $(\triangle)$

Environmental Science and Policy, University of California,

Davis,

Davis, CA 95616, USA

e-mail: jsanchirico@ucdavis.edu

\section{J. N. Sanchirico}

University Fellow, Resources for the Future,

Washington, DC 20036, USA

\section{P. Mumby}

Marine Spatial Ecology Lab, School of BioSciences,

University of Exeter,

Prince of Wales Road,

Exeter EX4 4PS, UK species utilize habitats and that this research is not just important for ecological science, but it can and will influence ecosystem service values that, in turn, will impact coastal land-use decisions. While refining valuation methods is not necessarily going to lead to more rational coastal landuse decisions, it will improve our understanding on the ecological-economic mechanisms that contribute to the value of our natural capital assets.

Keywords Bioeconomic - Ecosystem services .

Mangroves · Coral reefs · Sea grass · Coastal land-use ·

Ontogenetic migrations

\section{Introduction}

Habitats and the ecosystem services they provide are part of the world's portfolio of natural capital assets (Daily et al. 2000; Balmford et al. 2002). Like many components of this portfolio, it is difficult to assess the full economic value of these services, which tends to overemphasize the value of extractive activities such as coastal development that are easier to measure.

Mangroves are a classic example of a globally threatened habitat that provides harvestable products (i.e., fish, wood) and ecological services (hurricane protection; trapping of sediment which enhances water quality; Barbier et al. 2008). The primary threats to mangroves are coastal development, conversion to shrimp aquaculture, pollution, and wood harvesting (Valiela et al. 2001). Several authors attribute current trends in the loss of mangroves to the failure to place an appropriate economic value on their ecological services (Ronnback 1999; Barbier 2000) and that proper mangrove valuation is the first step in the sustainable development of mangrove ecosystems (Lugo 2002). 
While we acknowledge that placing values on nature is a controversial exercise (McCauley 2006), we take a pragmatic perspective that is grounded in the realization that habitats are currently being valued in cost-benefit analysis, albeit rather imprecisely. Examples from the United States include natural resource damage assessment cases under the US Oil Spill Prevention Act of 1990, permitting decisions under Section 404 of the US Clean Water Act, and designation of Essential Fish Habitat under the US Magnuson-Stevens Fishery Conservation and Management Act.

To arrive at the total economic value of a habitat, we need to measure all of the use and nonuse values of their services (Bockstael et al. 2000; Heal et al. 2005)—values that depend on economic factors, such as marketable services (e.g., fish, timber, carbon) and nonmarket services (e.g., biodiversity), and ecological factors, such as growth rates, density-dependence mechanisms, and species-habitat associations. For example, there is the distinction between obligate use, where a particular habitat type is absolutely necessary for the species survival, and facultative use, where a habitat supplements a species growth, but the habitat is not necessary for survival (Ronnback 1999).

Valuing habitats is not a new endeavor, and previous studies have focused on assigning value to a habitat's role in the "production" of a marketable commodity, such as commercially harvested fish (Lynne et al. 1981; Freeman 1991; Barbier 2000, 2007; Barbier et al. 2002). An important finding is how the management institution, such as open-access, common property, or sole ownership, affects the value of the services provided by the habitat (Freeman 1991; Barbier et al. 2002). For example, under open-access conditions where the returns to the fishery are dissipated in equilibrium, the value of the fishery with or without mangroves is equal to zero in equilibrium. Smith (2007) illustrates, however, that although the equilibrium value is zero, there is potential for value generated in the transition to the equilibrium.

Although these previous analysis of habitat-fishery linkages provide analysis relevant to the particular ecosystems and question of interest, techniques have not previously been developed to incorporate the variable associations of species with habitats that often occur in nature. Ecologists have shown, for example, that many species utilize different habitats at different stages of ontogeny and that the use of these habitats is often facultative (Nagelkerken et al. 2002). For example, some commercially important coral reef fish, particularly those in the families snapper (Lutjanidae) and grunt (Haemulidae) spend their juvenile phase in sea grass beds then migrate to mangroves for a period of time before finally migrating to their adult reef habitat. In the absence of mangroves, these species migrate directly from sea grass beds to reefs. While the use of mangroves is mostly facultative by reef fish, ecosystems offering mangrove nurseries have a higher standing crop of adult reef fish (Nagelkerken et al. 2002; Mumby et al. 2004). Surprisingly, to our knowledge, there are no bioeconomic models that incorporate both facultative and obligate associations of species among multiple types of habitats.

Building on recent ecological studies of species-habitat linkages (Mumby et al. 2004; Harborne et al. 2006; Mumby 2006), we contribute to the science of valuing multiple types of habitats as natural capital, using mangroves, sea grass, and coral reefs as our model system. Our model does apply to other coastal ecosystems where species utilize multiple types of habitat in their life cycle. The contributions of the paper are: (1) to illuminate how key ecological variables and processes, including different species-habitat associations map into ecosystem service values and (2) to show how the valuation of these ecological processes maps into the opportunity cost of clearing the mangroves that can be used to inform decisions regarding coastal development (habitat clearing).

Our paper also contributes to the broader economicecological research goal that calls for the further development and refinement of production methods to measure and value ecosystem services (Heal 2000; Balmford et al. 2002; Heal et al. 2005; Kremen and Ostfeld 2005; Kareiva et al. 2007). With improved measurement, the possibilities to develop payment systems for ecosystem services and other conservation tools that take into account their total economic value are enhanced (Heal et al. 2005).

\section{Methods}

The key findings in Mumby et al. (2004) that guide the development of our bioeconomic model are: (1) the availability of different juvenile habitats (sea grass beds and mangroves) partly determine the biomass of adult fish on coral reefs because survival rates of juveniles vary among habitats; and (2) fish species-mangrove functional relationships in coral-reef systems tend to be facultative rather than obligate. In particular, we model a biological (fish) species whose adults are sedentary on a coral reef but which utilizes sea grass and mangrove habitats during its juvenile phase. Fishing pressure occurs on the reefs and is regulated under a licensed limitedentry fishery where the regulators are controlling the total level of fishing effort (or boats). We describe the biological and economic model and then the calculation of mangrove habitat value, based on mangroves serving as an input into the "production" of the fish population being harvested.

\section{Biological model}

New individuals recruit to the reef either directly from the sea grass beds or after an intermediate nursery stage within 
mangroves (Fig. 1). In any period, a share of the juveniles produced from the adult, reef-based population, denoted $N$, will return directly to the reefs after spending time in sea grass. Once these juveniles return to the reef, they are susceptible to increased (prey) mortality, and we define the survivorship rate for these juveniles as $S_{\mathrm{r}}$. Those juveniles in sea grass that do not migrate directly to the reef migrate instead to a mangrove patch that is accessible from both the sea grass and reef habitats. Based on field observations, Mumby (2006) assumes that the maximum distance fish migrate between mangroves and reefs is $10 \mathrm{~km}$. Consistent with Chittaro et al. (2005), the survivorship of the species that utilize the mangroves $\left(S_{\mathrm{m}}\right)$ is greater than the rate for species that go directly to the reef $\left(S_{\mathrm{r}}\right)$.

Because for policy analysis we need the incremental value of mangroves (Bockstael et al. 2000), we model the fraction of the population that returns to the reef from the sea grass beds $(1-W(M))$ or migrates to the mangroves $W(M)$ as a continuous function of the percent of cover, $M$, of the mangrove habitat. That is, when $M$ is equal to one, the mangrove habitat is pristine and as $M$ goes to zero, the coverage of mangroves decreases toward zero. We deviate from the Mumby et al. (2004) study that measured the effect of mangroves in terms of mangroves being present or absent within a certain distance of the reef and mangroves. The continuous specification of $W(M)$, therefore, is not empirically verified, but it seems likely that the mangrove coverage in the system will determine the number of juveniles using the mangroves as a refuge from predation. In our setting, the depth of the mangrove habitat is less important than the coastal perimeter of habitat, as most species remain within the edge area. Aburto-Oropeza et al. (2008) found the perimeter to be more valuable in Mexican reefs.

Our formulation is consistent with species-choosing habitats to improve their survivorship. For example, the ability of larval reef fishes to sense the presence of

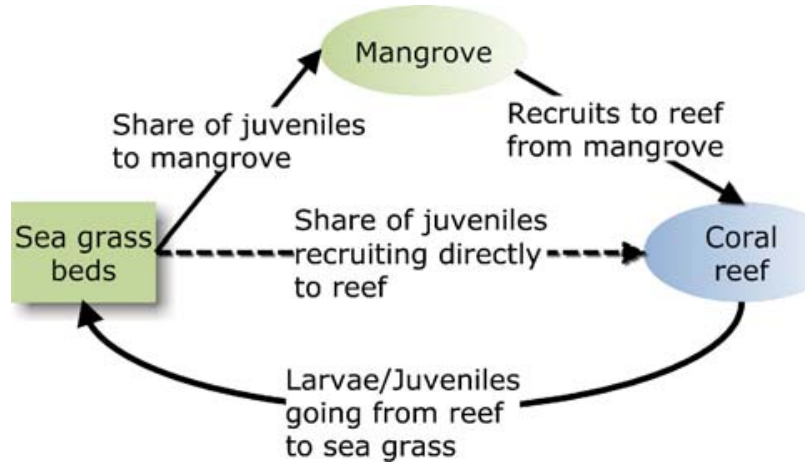

Fig. 1 Schematic of a facultative association Note: Juveniles going from reef to sea grass is $J(N)$, share of juveniles to mangrove is $W(M)$ $J(N)$, share of juveniles going directly from the sea grass beds to the reef is $(1-W(M)) J(N))$, recruits to the reef in period $t$ is $R(t)=W(M)$ $\left.J(N) S_{\mathrm{m}}+(1-W(M)) J(N)\right) S_{\mathrm{r}}$, where $S_{\mathrm{m}}$ and $S_{\mathrm{r}}$ are the survivorship rates in the mangroves and reef, respectively settlement habitat and swim toward it is well established, either using sound (Simpson et al. 2005) or chemical signatures of different habitats (e.g., sea grass; Arvedlund and Takemura 2006). What is not clear, however, is the type of functional responses $W(M)$ that would follow as the coverage of mangroves changes. For now, we only impose the following properties: $W(0)=0, W(1) \leq 1, d W(M) / d M>0$. The first says that if there are no mangroves, the fraction of juvenile fish utilizing them is zero. The second allows for the possibility that even though the mangroves are pristine, some of the juveniles might recruit directly from sea grass to reef. The third states that the fraction utilizing the mangroves increases as the coverage of mangroves increases, everything else being equal. This would be the case, for example, if the chemical signatures or sound increased with the coverage of mangroves.

In any period, recruitment to the reef depends on the number of larvae/juveniles produced from the standing stock of adults on the reef in the previous period, the share of juveniles utilizing the mangroves or reefs, and the relative survivorship of these individuals. Putting these together, recruitment is equal to $R(t)=J(N(t))\left(W(M) S_{\mathrm{m}}+\right.$ $\left.(1-W(M)) S_{\mathrm{r}}\right)$, where $J(N(t))$ is the number of larvae/ juveniles produced in any period from the current population of adults on the reef. Specifically, $J$ is represented as $J(N(t))=\theta N^{\alpha}$ where $\alpha$ and $\theta$ are non-negative. Egg production is often thought to follow increasing returns to scale per individual, and we can model this with the assumption that $\alpha$ is greater than one. Theta could be modeled as a function of the coverage and quality of the sea grass beds, but for simplicity, we assume that it is a constant parameter.

As just presented, $R(t)$ captures a facultative association dependent on the levels of survivorship in reef and mangrove habitats. In such a setting, the mangroves provide an enhancement to survivorship, but the reefs are still able to supply a growing population if mangroves are absent. The obligate relationship occurs when survivorship on the reef, $S_{\mathrm{r}}$, is equal to zero. In this case, the reef population is directly dependent on the recruits from the mangroves, and if the mangroves are completely removed, the population will go extinct.

Next, we map the flow of recruits into the fishable population of adults on the reef. The instantaneous rates of change for the reef's adult fish stock is: $\mathrm{d} N / \mathrm{d} t=F(N, g(R))-$ $q E^{T} N$, where $q E^{T} N$ is the catch, $q$ is a catchability coefficient, $E^{T}$ is the aggregate fishing effort level, $F(N, g$ $(R))$ is the growth of adult biomass on the reef, and $g(R)$ is the recruitment function to the reef. Because we assume that the juvenile/larval phases of the species life cycle exhibit fast dynamics while the dynamics of adult biomass on the reef are slow, we only need to track the population on the reefs rather than the populations in the different 
habitats. This gains us tractability and could be generalized easily.

There are many possible specifications for $F(N, g(R))$. One issue is whether recruits face two density-dependent processes during the settlement phase. That is, recruits can compete with other recruits for space and resources during settlement, and they might also compete with the standing stock of adults on the reef (it should be borne in mind that the "recruits" are not postlarvae, but individuals of nearadult or adult size that have migrated from other habitats and are therefore more likely to utilize similar resources to resident adults). We allow for this possibility by specifying the following growth function: $F(N, R)=g(R)(1-N / K)$, where $K$ is the carrying capacity on the reef. The unexploited equilibrium of our growth equation (e.g., $E^{T}=0$ ) occurs when the adult biomass level is equal to the reef's carrying capacity. This holds regardless of the specification of $g\left(R_{\mathrm{i}}\right)$. It is important to note, however, that mangrove coverage will affect the exploited equilibrium $\left(q E^{T} N_{\mathrm{i}}>0\right)$ in nontrivial ways. Mangroves in our formulation increase the growth rate on the reef in a nonlinear manner, where greater coverage of mangroves leads to faster recovery of the reef populations.

Following Armsworth (2002), we assume that $g(R)=$ $b_{1} R_{\mathrm{i}} /\left(1+b_{2} R_{\mathrm{i}}\right)$. This implies that recruits enter the reef according to a Beverton-Holt recruitment function where $b_{1}$ describes the survival rate at low densities, and $b_{1} / b_{2}$ is the saturation limit. With $b_{2}=0$, the recruits compete only with the standing stock of adults during settlement.

Putting the pieces together, the biological growth dynamics are:

$$
\frac{\mathrm{d} N}{\mathrm{~d} t}=\left(\frac{b_{1}\left(\theta N^{\alpha}\left(W(M) S_{\mathrm{m}}+(1-W(M)) S_{\mathrm{r}}\right)\right.}{1+b_{2}\left(\theta N^{\alpha}\left(W(M) S_{\mathrm{m}}+(1-W(M)) S_{\mathrm{r}}\right)\right.}\right)\left(1-\frac{N}{K}\right)-q E^{T} N
$$

\section{Economic model}

The economic value for the mangrove habitat as captured through fishery-habitat linkages depends on the same economic factors that contribute to fishing profits including ex-vessel fish prices, fishing technology, fishing costs, and fishing effort levels. For example, if the price of the fish being caught is low, everything else being equal, we would expect that the value of the mangrove through the fisheryhabitat linkage would correspondingly be low.

The relationship with respect to fishing effort is more complex, however, because it depends on regulations regarding entry and exit of fishing effort and the characteristics of the fishing operation. If the fishery is under openaccess conditions where fishermen are free to enter and exit (Smith 1969), then, in the long-run, the equilibrium profits are dissipated (Gordon 1954). Dissipating all profits in the long-run is also possible when the regulator restricts a single dimension of fishing effort, such as vessel length, as fishermen will continue to invest in the unrestricted inputs, such as vessel power or hours worked, to give them a competitive advantage (Wilen 1985; Homans and Wilen 1997). On the other hand, if the regulator charges a landings tax or tax per unit of effort in the fishery, then gross fishing profits (that is before the taxes are netted out) are not dissipated (Sanchirico 2003). Finally, allocating shares of the catch to fishermen has also been shown to lead to positive profits (Newell et al. 2005). When the value of the fishery is not dissipated in equilibrium, corresponds to situations where the value of mangroves is positive. Additional complexities arise when one (appropriately) considers not just the equilibrium value, but the value generated during the transitional from one equilibrium to another (Smith 2007).

Because our focus is on mapping ecological behavior to habitat value, we abstract away from many of these complexities and utilize a parsimonious economic model. Although the issues just described affect the magnitude of the habitat-fishery values and therefore are critical in an empirical analysis of ecosystem services, these factors do not affect our theoretical conclusions. The general recipe for mapping ecosystem functions to services to coastal land uses is not affected.

We assume that the coral reef fishery consists of a licensed limited-entry system, where the single input factor fishing effort is capped by a regulatory agency, and the fishing vessels must pay a fee to participate. In our setting, the fee is determined endogenously depending on the economic conditions in the fishery. Although many fisheries around the world have a limit on the number of vessels allowed to fish (OECD 1997), we are not aware of any that set the license price using economic analysis. We choose this setup because by varying the total level of effort in the fishery, we can simulate the levels of fishing effort associated with different institutional systems from openaccess (zero license price) to more restrictive systems that includes the level of effort that maximizes net benefits from the fishery (Sanchirico and Wilen 2002; Sanchirico 2004).

We assume that the catch from this reef makes up a small portion of the region's supply of fish, and therefore, the price of fish is exogenous and constant. We have relaxed this assumption and the results with respect to the differences between the values generated by obligate and facultative behaviors are qualitatively identical. We maintain the exogenous price assumptions because it permits closed-form analytical solutions.

Gross fishing profit $(\pi)$ is a function of the level of effort permitted by the regulator $\left(E^{T}\right)$ and the size of the fish stock on the reef $(N)$. Specifically, gross fishing profit is: $\pi\left(E^{T}, N\right)=p q E^{T} N-c E^{T}$ where $p$ is the ex-vessel price of 
fish, $c$ is cost per unit of effort that includes the opportunity cost of fishing capital plus fishing costs. In our licensed limited-entry setting, the relevant measure of long-run equilibrium fishing profits nets out the license price $(L)$ or $\pi\left(E^{T}, N, L\right)=p q E^{T} N-c E^{T}-L E^{T}$. We can also interpret the license price as a tax per unit of effort but in such a setting, the regulator would set the tax and fishing effort is the free variable. We model the level of fishing effort as exogenous, and the license price is determined endogenously.

If the regulator sets $E^{T}$ equal or greater than the level that corresponds to the open access level $\left(E^{T \infty}\right)$, then $L$ will equal to zero (a negative license price does not make sense; Sanchirico and Wilen 2002). In this way, our setup nests the open-access equilibrium. If $E^{T}$ is less than the open access level, then the economic returns (producer surplus or rent) per unit of effort are positive and equal to $L$. Furthermore, as $E^{T}$ approaches $E^{T \infty}$, the license price goes to zero, everything else being equal.

\section{Measuring the value of mangroves}

To determine the contribution of mangroves to the equilibrium value of the fishery and to the costs and benefits of coastal land-use decisions, we make the following calculations. First, we solve for the long-run equilibrium of fish stock, $N^{\mathrm{eq}}$, and the license price, $L^{\mathrm{eq}}$, for a given level of total fishing effort. This occurs where net profits $(\pi)$ are zero, and Eq. 1 is at rest for each level of $E^{T}$. Specifically, we have the following equations that define the equilibrium $\left(N^{\mathrm{eq}}, L^{\mathrm{eq}}\right)$ :

$$
\begin{array}{r}
\left(\frac{b_{1}\left(\theta N^{\alpha}\left(W(M) S_{\mathrm{m}}+(1-W(M)) S_{\mathrm{r}}\right)\right.}{1+b_{2}\left(\theta N^{\alpha}\left(W(M) S_{\mathrm{m}}+(1-W(M)) S_{\mathrm{r}}\right)\right.}\right)\left(1-\frac{N}{K}\right)-q E^{T} N=0 \\
p q E^{T} N-c E^{T}-L E^{T}=0
\end{array}
$$

Recall that the facultative association occurs when $\left(S_{\mathrm{m}}\right.$, $\left.S_{\mathrm{r}}\right)>(0,0)$, and the obligate occurs when $S_{\mathrm{m}}>0$ and $S_{\mathrm{r}}=0$.

Second, we calculate the equilibrium total value of the fishery $(V)$, which is equal to the level of effort times the per unit value of effort $\left(L^{\mathrm{eq}}\right)$, where $V\left(E^{T}, M\right) \equiv E^{T} \times L^{\mathrm{eq}}\left(E^{T}, M\right)$. We then investigate how the total value changes for different levels of fishing effort and mangroves. The analysis is done for both facultative and obligate associations. Because we are only focusing on the equilibrium value, we find that at the open-access effort level $\left(E^{T \infty}\right)$ that $V\left(E^{T}, M\right)$ is equal to zero regardless of the different habitat associations. A similar conclusion with respect to the equilibrium returns under open-access conditions with and without marine reserves is found in Sanchirico and Wilen (2001).

Finally, we investigate the implications of different habitat associations on coastal land use decisions by deriving the marginal opportunity cost (foregone fishing value) from a loss in mangrove coverage. The marginal opportunity cost is simply the change in the total value of the fishery with a change in the mangroves $\left.\left(\mathrm{d} V\left(E^{T}, M\right) / \mathrm{d} M\right)\right)$.

When we calculate the opportunity cost of clearing mangroves, we are in essence drawing out the supply curve of mangroves. In theory, the market for clearing mangroves will be at equilibrium when the supply curve is equal to the marginal benefit (or demand) curve derived from the economic values associated with converting the mangroves. The intersection of the demand and supply curve yields the level of mangrove conversion. It would not be the level that maximizes net social benefits, however, because we are not considering all of the opportunity costs associated with mangrove conversion (e.g., flood control, water quality, storm protection). A similar analysis was recently illustrated in Barbier et al. (2008).

\section{Results}

To derive analytical results on the value of habitat, we assume that the recruits only compete with the standing stock on the reefs during the settlement process $\left(b_{2}=0\right)$ and that the number of juveniles is linearly related to the size of the population $(\alpha=1)$. Under these assumptions, the closed form equilibrium solutions for the fish stock and the license price are:

$N^{\mathrm{eq}}=K\left(1-\frac{q E^{T}}{\theta b_{\mathrm{o}}\left(S_{\mathrm{r}}+\left(S_{\mathrm{m}}-S_{\mathrm{r}}\right) W(M)\right)}\right)$

$L^{\mathrm{eq}}=p q K\left(1-\frac{q E^{T}}{\theta b_{\mathrm{o}}\left(S_{\mathrm{r}}+\left(S_{\mathrm{m}}-S_{\mathrm{r}}\right) W(M)\right)}\right)-c$

Equation 3 shows that the equilibrium fish stock $\left(N^{\text {eq }}\right)$ decreases as fishing effort $\left(E^{T}\right)$ increases. The effect of fishing effort on the equilibrium population, however, is muted by the presence of the mangroves (see Fig. S1 in supplementary material). That is, for higher levels of mangroves, we find that the equilibrium population on the reef is higher at the same effort level (note: $M_{2}>M_{1} \rightarrow$ $W\left(M_{2}\right)>W\left(M_{1}\right)$ ). We also find that higher levels of fishing effort can be supported with greater levels of mangroves.

What are the potential implications of these findings? Suppose, for example, if we are at an effort level, $E_{2}^{T}$ and the level of mangroves is $M_{2}$, then the equilibrium population level is $N_{2}^{e}$. If, however, the mangroves are cleared and effort is not changed simultaneously, it is very possible that $E_{2}^{T}$ will drive the population extinct. Mangroves, therefore, provide an important buffer against excess levels of fishing effort (Kareiva et al. 2007). The 
magnitude of the "buffering" effect is calculated by $\partial N^{\text {eq }}$ $\partial M$, which is equal to:

$\frac{\partial N^{\mathrm{eq}}}{\partial M}=\left(\frac{q E^{T}\left(S_{\mathrm{m}}-S_{\mathrm{r}}\right)}{\theta b_{\mathrm{o}}\left(S_{\mathrm{r}}+\left(S_{\mathrm{m}}-S_{\mathrm{r}}\right) W(M)\right)^{2}}\right)\left(\frac{\partial W(M)}{\partial M}\right)$

Equation 5 shows that the size of the buffer depends on the bump in survivorship $\left(S_{\mathrm{m}}-\mathrm{S}_{\mathrm{r}}\right)$, how species utilize the habitat $(\mathrm{d} W(M) / \mathrm{d} M)$, the sea grass effect $(\theta)$, and the fishing effort level $\left(E^{T}\right)$. Sea grass beds have a similar buffering effect $\left(\mathrm{d} N^{\mathrm{eq}} / \mathrm{d} \theta>0\right)$. This result highlights the value of ecological research on understanding the differences in survivorship across habitats $\left(S_{\mathrm{m}}, S_{\mathrm{r}}, \theta\right)$ and how species find and utilize the habitats $(W(M))$ for species conservation.

Total value of the fishery

How do mangroves impact the total value of the fishery? Under our assumptions, we can solve for the total value, which is equal to:

$$
\begin{aligned}
V\left(E^{T}, M\right) & =L^{\mathrm{eq}} E^{T} \\
& =\left(p K q\left(1-\frac{q E^{T}}{\theta b_{1}\left(S_{\mathrm{r}}+\left(S_{\mathrm{m}}-S_{\mathrm{r}}\right) W(M)\right)}\right)-c\right) E^{T}
\end{aligned}
$$

We illustrate in Fig. 2 panel A and B Eq. 6 as a function of the total effort level for different levels of mangrove availability. For the facultative case (panel A), the optimal level of effort in the fishery (level where the total value is at its maximum) increases as the amount of mangroves increase. We also see that for a given level of effort, the value of the fishery is higher with mangroves than without. Furthermore, in some cases, the value of the fishery would be zero if it were not for mangroves providing a bump in survivorship. The mangrove and sea grass buffers, therefore, translate directly into value. We also find that the total value of the fishery increases with the price of fish $(p)$, catchability of the fish $(q)$ and decreases with the cost of fishing effort, $c$.

For a given availability of mangroves, total fisheries value is higher for all levels of fishing effort when the association is facultative rather than obligate (Fig. 2B). Under a facultative relationship, the habitat supplements recruitment directly to the reef, and together, the effect of recruitment occurring through two pathways is larger than when there is only recruitment via the mangroves. This effect would be reduced somewhat if the recruits competed with one another during settlement $\left(b_{2}>0\right)$.

In order to explore the influence of mangrove availability on fishery value, we impose the additional property that the mangrove function $(W(M))$ increases at a decreasing rate in mangroves $\left(\mathrm{d}^{2} W(M) / \mathrm{d} M^{2}<0\right)$. Ecologically, this relationship can be due to competition among juveniles for mangrove resources or reflect the difficulty in finding mangroves as their availability declines.

Figure 2c and d shows that for a given effort level, the total value of the fishery increases as the mangrove
Fig. 2 Fishery-habitat associations and total value. a The total value of the fishery for different fishing effort levels and levels of mangroves for a facultative association. The solid line (gray) parabola is drawn for the case where there are no mangroves $(M=0)$. b The value of the fishery in an obligate and facultative association holding the level of the mangroves fixed across the two cases, where $O$ is for obligate and $F$ is for facultative; c The value of the fishery over the range of mangroves for different effort levels under a facultative association, where $E_{0}^{T}<E_{1}^{T}<E_{2}^{T}<\ldots<E_{6}^{T}<$ $E_{7}^{T} ; \mathbf{d}$ The value of the fishery over the range of mangroves for different effort levels under an obligate association, where $E_{\mathrm{o}}^{T}<E_{1}^{T}<E_{2}^{T}<\ldots<E_{4}^{T}$ a

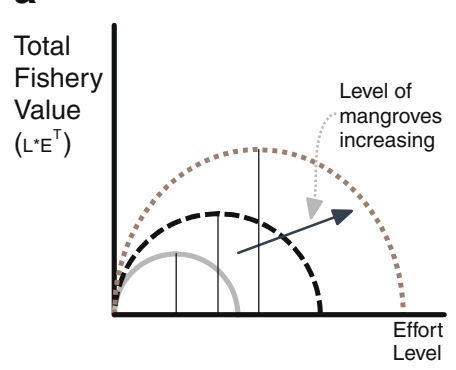

c

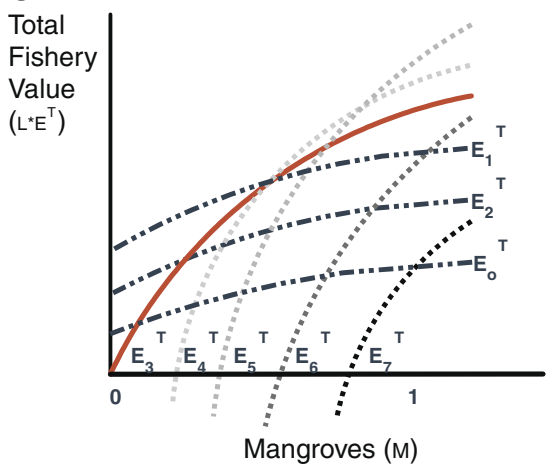

b

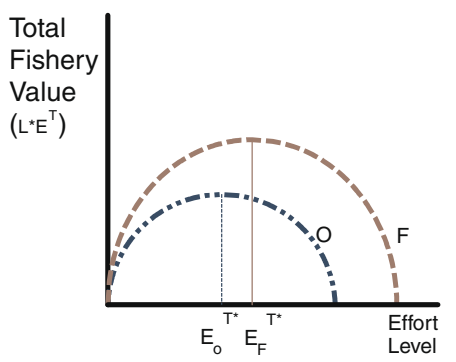

d

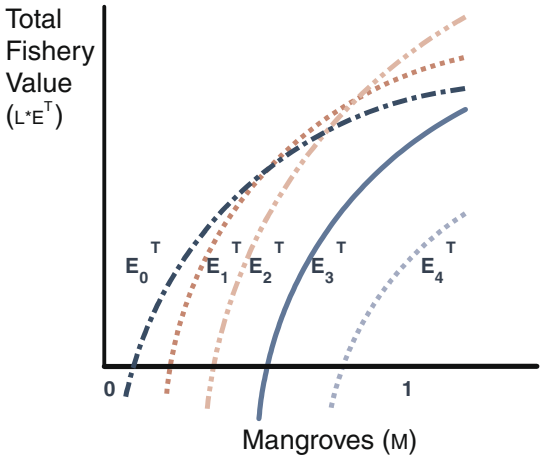


availability increases but at a decreasing rate. We also find that a complex interaction emerges among the level of fishing effort, mangrove coverage, and total fishery value, where the effort level that results in the highest total value depends critically on the level of the mangrove coverage. We also find that the greater the amount of fishing effort level, the greater is the minimum threshold of mangrove coverage needed to ensure that the value of the fishery is positive. A similar result holds for the facultative association, but it takes higher effort levels than in the obligate setting for this to occur. Such a situation is likely to occur if the decision on whether to clear mangroves ignores their value for fishery production.

Average value of the fishery

Because many studies of habitat valuation use average values (Costanza et al. 1997), we also show how the average value of the fishery with respect to fishing effort ( $V$ $\left.\left(E^{T}, L\right) / E^{T}=L^{\mathrm{eq}}\right)$, and the average value with respect to mangroves $\left(V\left(E^{T}, L\right) / M\right)$ varies with the coverage of mangroves (Fig. 3). Intuitively, the license price $\left(L^{\mathrm{eq}}\right)$ is the amount that a vessel owner would be willing to pay (e.g., per hour) to fish on the reef. In the facultative case (panel A) and the obligate setting (panel B), the shape of the license price increases at a decreasing rate in the level of mangroves, which is driven by the properties of $W(M)$.
We also find that there is endogenous minimum threshold of mangroves needed at a given fishing effort level for the fishery to be become profitable. The threshold is determined by setting $L^{\mathrm{eq}}$ equal to zero and solving for the critical level of mangrove coverage that is a function of economic and ecological conditions in the fishery. Applying the implicit function theorem, we can show that the threshold increases with greater levels of fishing effort, and decreases with higher survivorship in the mangroves $\left(S_{\mathrm{m}}\right)$ and higher quality of the sea grass beds $(\theta)$. Finally, the amount a vessel owner would be willing to pay to fish increases with the coverage of mangroves, which highlights the potential for the fishery to help fund the conservation of mangroves or the development of a payment for ecosystem service scheme.

Figure $3 \mathrm{c}$ and $\mathrm{d}$ illustrates the average value with respect to the coverage of mangroves $\left(V\left(E^{T}, L\right) / M\right.$ or $\left.V / M\right)$ in a facultative and obligate setting, respectively. Under both settings, $V / M$ varies based on the level of fishing effort. For example, for very low levels of effort, $V / M$ increases as fishing effort is increased, and at higher levels of fishing effort, it decreases as fishing effort is increased. For expositional purposes, we illustrate the latter case. The threshold level found in Fig. 3a and b is identical to the ones illustrated in panel $\mathrm{c}$ and $\mathrm{d}$, as it is determined by the license price in both cases. The only exception is the facultative case when the value of the license remains positive at $M=0$ (in panel a, the vertical intercept is positive). In this case, $V / M$ goes to positive infinity as $M \rightarrow 0$.
Fig. 3 Fishery-habitat associations and average value. a Average value of the fishery with respect to fishing effort under a facultative association. b Average value under an obligate association. c The average value with respect to mangrove coverage under a facultative association. $\mathbf{d}$ The average value in an obligate setting. In all cases, the following relation holds: $E_{1}^{T}<E_{2}^{T}<E_{3}^{T}$ a

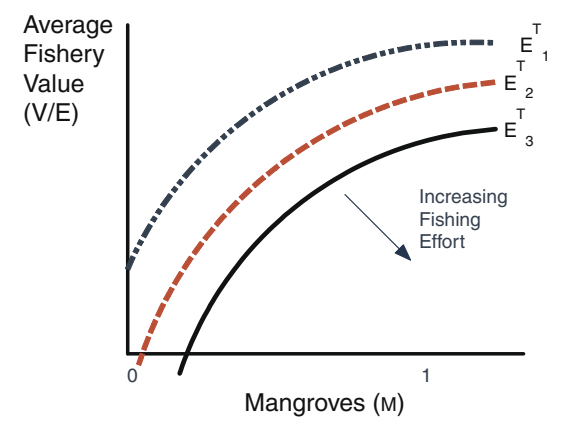

C

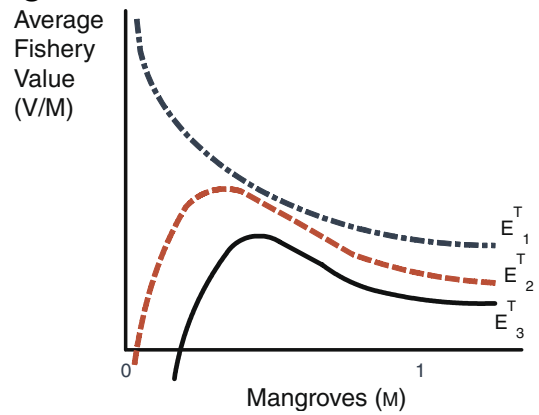

b

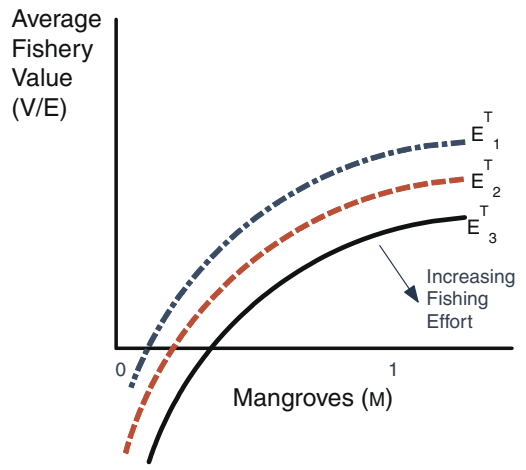

d

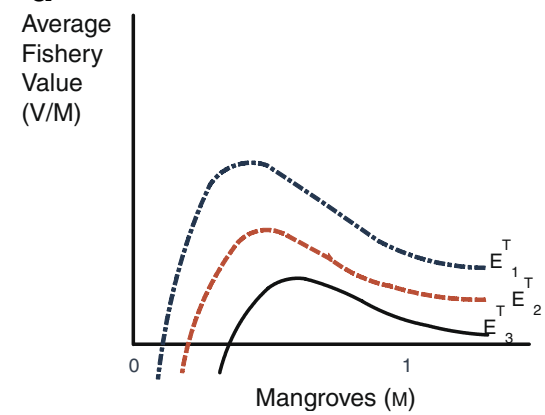


Opportunity cost of clearing mangroves (marginal values)

Beyond illustrating how the value of the fishery is tied to the habitat and varies based on habitat associations, the ecosystem service values can inform cost-benefit analyses of whether to clear or modify a particular habitat. Imagine, for example, a coastal planner confronted with the following decision: whether to allow a tourism development project to go ahead and if so, how large an area of the coastal environment to convert? Although the costs of converting the mangroves include lost storm protection, lost nonuse values, etc (Barbier et al. 2008), we focus here on the opportunity costs due to the reduced profits from fishing the species that depend on them (Brown and Roughgarden 1997; Bockstael et al. 2000).

The opportunity costs of converting the mangroves can be thought of as the cost of supplying mangroves (really, the coastal area) to the development market. On the other hand, there are benefits to the development project. By paring the opportunity cost (or supply function of mangroves) with a hypothetical demand for mangrove habitat based on the (marginal) benefits, we investigate how the level of clearing undertaken by a rational coastal planner varies with the different species-habitat associations and with different fishing effort levels (level of clearing is determined at the intersection of the demand and supply curves). The opportunity costs of mangroves are also the amount a fishermen would be willing to pay (ecosystem service payment) to avoid the clearing.

Specifically, the opportunity costs are $\mathrm{d} V\left(E^{T}, \mathrm{~L}\right) / \mathrm{d} M$, which is equal to:

$$
\frac{\partial V\left(E^{T}, M\right)}{\partial M}=\frac{p K q^{2} E^{T^{2}}\left(S_{\mathrm{m}}-S_{\mathrm{r}}\right)}{\theta b_{1}\left(S_{\mathrm{r}}+\left(S_{\mathrm{m}}-S_{\mathrm{r}}\right) W(M)\right)^{2}} \frac{d W(M)}{d M}
$$

For a facultative association, we find that the opportunity cost increases with the amount of mangroves cleared and that it increases with increased fishing effort levels (see Fig. S2 in supplementary material). The coastal land use implication is that with higher fishing effort levels, it pays to clear less habitat, everything else being equal. Qualitatively similar results hold for the obligate association. It is also easy to show that the opportunity costs decrease with improved conditions in the sea grass beds $(\mathrm{d} V / \mathrm{d} M \mathrm{~d} \theta<0)$. This is because with greater numbers of juveniles surviving in the sea grass beds $(\theta \uparrow)$, the number of recruits to the reef is less dependent on the predation refuge in the mangroves.
Fig. 4 Opportunity costs and coastal land-clearing. a and $\mathbf{b}$ The opportunity cost of clearing mangroves in mangrove space (a) and in fishing effort space (b). The intersection of the hypothetical demand curve and the opportunity cost curve determines the share of the mangroves cleared. a, b $\mathrm{F}$ and $\mathrm{O}$ represent facultative and obligate, respectively. $\mathbf{c}$ The potential differences between using average vs. marginal values of mangroves in coastal land-use decisions where $V / M$ is the average value of the fishery with respect to mangroves, and $\mathrm{d} V / \mathrm{d} M$ is the marginal value (opportunity cost) with respect to mangroves a

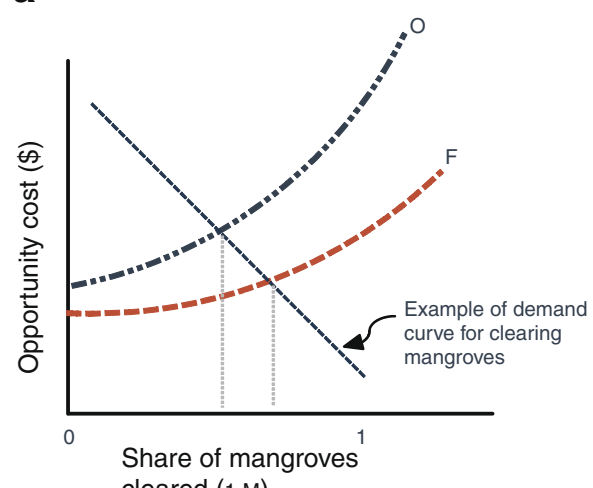
cleared (1-M)

C

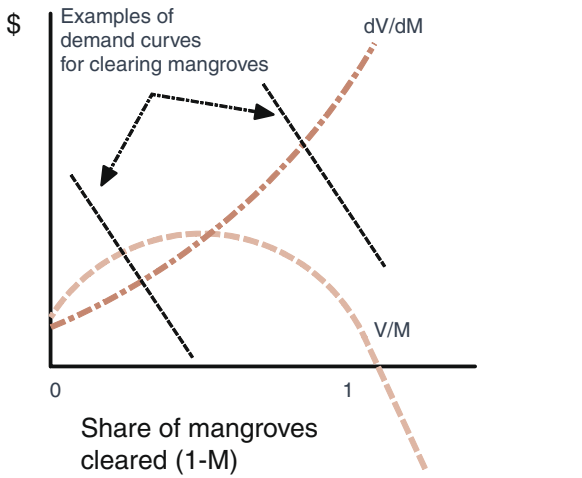

b

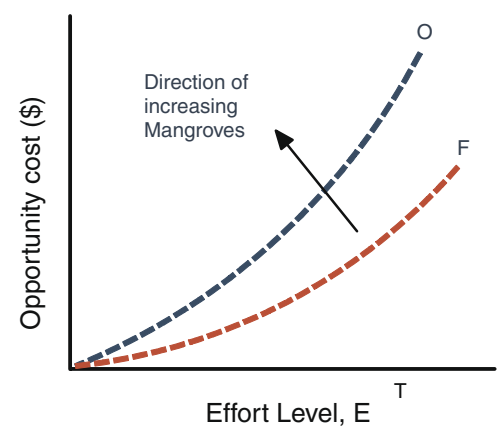


We find that the opportunity cost is higher for obligate than for facultative associations (Fig. 4a). Therefore, even though the total and average values from fishing were lower for the obligate relationship, we find that the marginal value is higher due to the greater (marginal) effect that mangroves have on the value of the fishery in the obligate rather than facultative setting. An obligate habitat association, therefore, results in less conversion of the coastal environment than when the association is facultative.

Recall that mangroves become more important for persistence of the population when excessive fishing effort levels are applied to the reef because the mangroves can directly offset the negative impacts of fishing effort. The "buffering" effect identified earlier translates directly into value, as is illustrated in Fig. 4b where the opportunity costs of clearing the mangroves increase with increases in fishing effort.

We also show in the supplementary material that, as the availability of mangroves reaches zero, the opportunity cost in the obligate case goes to positive infinity, while in the facultative case, it goes to a finite level. In the obligate setting, therefore, it never pays to clear the entire mangrove habitat, while under a facultative association, that result is possible depending on the other opportunity costs associated with clearing mangrove habitats.

Our results illustrate the importance of utilizing the incremental (or marginal) value for policy decisions (Bockstael et al. 2000), as opposed to total or average values that are commonly used in habitat valuation studies (Costanza 1997). For instance, consider the case in Fig. 4c, where we represent the marginal costs $\mathrm{d} V\left(E^{T}, L\right) / \mathrm{d} M$, the average costs V/M for an obligate setting, and two hypothetical demand curves for coastal development projects. If the mangroves are relatively pristine, and the regulator uses the average value rather than the marginal, then the result can be less clearing that what is economically efficient. On the other hand, if the mangroves are not intact, then using the average value that first increases and then decreases as the coverage of mangroves goes to zero can result in clearing more acres than what would be cleared if the marginal opportunity costs are employed. Although not illustrated, other possible scenarios include where $V / M$ is everywhere above or below $\mathrm{d} V\left(E^{T}, L\right) / \mathrm{d} M$.

Opportunity costs evaluated at the optimal effort level

We have been calculating the opportunity cost taking the effort level as fixed by a regulator. But another way to measure the opportunity cost is to substitute in the optimal effort level for each level of mangrove availability (see Fig. $2 \mathrm{c}$ and d), such that we are looking at the change in the optimal value of the fishery for a change in mangroves. The opportunity costs at the optimal effort levels are equal to:

Facultative :

$$
\left.\frac{d V(M)}{d M}\right|_{E^{T}=E^{T *}}=\frac{\theta b_{1}(c-p K q)^{2}\left(S_{m}-S_{r}\right) W^{\prime}(M)}{4 p k q^{2}}
$$

Obligate :

$$
\left.\frac{d V(M)}{d M}\right|_{E^{T}=E^{T *}}=\frac{\theta b_{1}(c-p K q)^{2} S_{\mathrm{m}} W^{\prime}(M)}{4 p k q^{2}}
$$

Not surprisingly, the opportunity costs are a function of the mangrove coverage, which is still treated as exogenous to the fishery management decision. Comparing Eq. 8 and 9, the marginal opportunity costs in the obligate setting are larger than in the facultative setting, and the difference depends on the difference in the survivorship $\left(S_{\mathrm{m}}-S_{\mathrm{r}}\right) / S_{\mathrm{m}}$.

Overall, the qualitative properties do not change when we insert the optimal effort levels - the opportunity cost increases as the loss of mangroves increase. One important difference, however, is that in the obligate setting, the opportunity costs are finite as the coverage of mangroves goes to zero. The implication is that it is now possible that the benefits from clearing can outweigh the costs, even for very small levels of mangrove coverage. This stems from the fact that as the mangrove coverage declines, the optimal level of fishing effort to apply also decreases and with it so does the value of the fishery and the opportunity cost from clearing. Two points are worth noting about this result. First, we are not determining the economically optimal level of mangroves to conserve - such a calculation would need to investigate the total economic value associated with mangroves. Second, the result highlights how coastal restoration activities map into the value of commercial fisheries and that there are incentives for the fishers to pay for coastal restoration activities.

Another interesting difference between the two cases can be seen by comparing Eqs. 7 and 8 . In particular, we find that there is a reversal on how the opportunity costs of mangroves vary with respect to changes in the quality of the sea grass beds $(\theta)$. When fishing effort is set exogenously by the regulator, the opportunity cost decrease with improvements in the quality of the sea grass. On the other hand, when the optimal effort level is employed, the opportunity costs increase with changes in the sea grass conditions. In the latter case, improvements in sea grass beds translate into greater optimal effort levels (see equation S.6 in supplementary material). Higher levels of optimal fishing effort, in turn, increase the total value of the 
fishery which results in higher opportunity costs. This reversal is a multiple-habitat analog to the findings on the importance of the institutional setting in the previous single habitat analyses (Barbier 2000).

\section{Discussion}

Measuring values of ecosystem services requires understanding how ecological "production" functions lead to economic values (Heal et al. 2005; Kremen and Ostfeld 2005), often as a result of complex spatially dependent processes such as ontogenetic migration. The scarcity of bioeconomic models that can both illuminate how ecosystem service values of habitats are generated in such settings and illustrate how species-habitat associations affect these values is therefore surprising. To fill this gap, we developed a stylized economic-ecological model of species-habitat associations that nests both obligate and facultative behaviors.

It is important to point out that not all species undertake ontogenetic migrations, as many species recruit directly to their adult habitat. However, many commercially important species do exhibit ontogenetic migration among habitats. In the Caribbean, for example, such migrations occur in at least one species of the most commercially important taxonomic groups on coral reefs: lobsters (e.g., Panulirus argus), conch (e.g., Strombus gigas), groupers (e.g., Epinephelus striatus), barracuda (Sphyraena barracuda), snappers (e.g., Lutjanus apodus), and grunts (e.g., Haemulon plumieri) (though species in the family Carangidae constitute an exception).

The strength of ontogenetic migrations exhibited by our Caribbean case study are perhaps particularly strong because the region's low tidal range allows mangrove prop-roots to remain permanently inundated, providing a predictable nursery habitat for juvenile fishes. However, the methods developed here can be generalized for any system in which ontogenetic habitat migrations occur. Even on coral reefs, not all migrations of commercially important species involve mangroves, though most utilize lagoons in some way. For example, sea grass beds have been found to be more important than mangroves for reef fish in East Africa (Dorenbosch et al. 2005), and other lagoonal habitats are important for the humphead wrasse (Cheilinus undulatus) and squaretail coral grouper (Plectropomus areolatus) in Micronesia (Tupper 2007). It is worth noting, however, that compelling evidence of a positive relationship between the availability of mangroves and fisheries production has been found for two areas of the Indo-Pacific: Australia (Manson et al. 2005) and Thailand (Shinnaka et al. 2007).

In our analysis, we abstracted away from the important spatial aspects of ecosystem service values in order to derive closed-form analytical solutions. We are currently developing a spatially explicit model that nests our "one patch" model illustrated here. None of the qualitative properties we find differ with additional patches, but the spatial model does permit us to investigate the role of connectivity of habitats in a seascape.

Other important extensions are to introduce the role of time with particular attention on how coastal estuaries and bays (or lack thereof) contribute to rebuilding of marine populations (Swallow 1990), heterogeneity in intrahabitat quality (Aburto-Oropeza et al. 2008), and to introduce additional species into the analysis where some have facultative and some have obligate associations. For example, there are species of parrotfish that have either facultative, obligate, or no dependence on mangrove. Indeed, given the importance of parrotfish in grazing algae on coral reefs and therefore enhancing coral recruitment, mangroves may play an additional role in maintaining a high-quality reef habitat for fisheries (Mumby and Hastings 2008). Lastly, it is not clear ex ante how adding, for example, predator-prey interactions will affect the opportunity cost. A predator that has a facultative association and eats prey that has an obligate, for instance, could result in an opportunity cost that is less than the sum of its parts.

Although we use a highly stylized bioeconomic model to map ecosystem functions to services, our qualitative findings highlight the importance of additional ecological research into how species utilize habitats-a finding that applies to more than just sea grass-mangroves-coral reef ecosystems. As we have demonstrated, this research is not just important for ecological science, but it can and will influence ecosystem service values that, in turn, will impact coastal land-use decisions. While refining valuation methods is not necessarily going to lead to more rational coastal landuse decisions, it will improve our understanding on the ecological-economic mechanisms that contribute to the value of our natural capital assets.

Acknowledgements We thank Geoff Schester for excellent research assistance and seminar participants at the AFS meetings in San Francisco (2007) and in the Ecology and Evolution Seminar Series at UC Davis (Oct 2007). The authors also thank their collaborators on the NSF-funded Bahamas Biocomplexity Project. This research was made possible by funding from NSF Biocomplexity in the Environment Program (OCE-0119976) and EPA Science to Achieve Results (R832223). We would also like to thank the comments of three anonymous reviewers.

Conflict of Interest Sanchirico and Mumby declare that there is no conflict of interest.

Open Access This article is distributed under the terms of the Creative Commons Attribution Noncommercial License which permits any noncommercial use, distribution, and reproduction in any medium, provided the original author(s) and source are credited. 


\section{References}

Aburto-Oropeza O, Ezcurra E et al (2008) Mangroves in the Gulf of California increase fishery yields. Proc Natl Acad Sci U S A 105 (30):10456-10459 doi:10.1073/pnas.0804601105

Armsworth PR (2002) Recruitment limitation, population regulation, and larval connectivity in reef fish metapopulations. Ecology 83 (4):1092-1104

Arvedlund M, Takemura A (2006) The importance of chemical environmental cues for juvenile Lethrinus nebulosus Forsskål (Lethrinidae, Teleostei) when settling into their first benthic habitat. J Exp Mar Biol Ecol 338(1):112-122 doi:10.1016/j.jembe.2006.07.001

Balmford A, Bruner A et al (2002) Economic reasons for conserving wild nature. Science 297(5583):950-953 doi:10.1126/science.1073947

Barbier EB (2000) Valuing the environment as input: applications to mangrove-fishery linkages. Ecol Econ 35:47-61 doi:10.1016/ S0921-8009(00)00167-1

Barbier EB (2007) Valuing ecosystem services as productive inputs. Econ Policy 22(49):177-229 doi:10.1111/j.1468-0327.2007.00174.x

Barbier EB, Strand I et al (2002) Do open access conditions affect the valuation of an externality? Estimating the welfare effects of mangrove-fishery linkages. Environ Resour Econ 21(4):343-367 doi:10.1023/A:1015129502284

Barbier EB, Koch EW et al (2008) Coastal ecosystem-based management with nonlinear ecological functions and values. Science 319(5861):321-323 doi:10.1126/science.1150349

Bockstael NE, Freeman AM et al (2000) On measuring economic values for nature. Environ Sci Technol 34:1384-1389 doi:10.1021/ es9906731

Brown GM, Roughgarden J (1997) A metapopulation model with private property and a common pool. Ecol Econ 22:65-71 doi:10.1016/S0921-8009(97)00564-8

Chittaro P, Usseglio P et al (2005) Variation in fish density, assemblage composition and relative rates of predation among mangrove, seagrass and coral reef habitats. Environ Biol Fishes 72:175-187 doi:10.1007/s10641-004-9077-2

Costanza R, d'Arge R et al (1997) The value of the world's ecosystem services and natural capital. Nature 387(6630):253-260 doi: $10.1038 / 387253 \mathrm{a} 0$

Daily G, Soderqvist T et al (2000) The value of nature and the nature of value. Science 289:395-396 doi:10.1126/science.289.5478.395

Dorenbosch M, Grol M et al (2005) Indo-Pacific seagrass beds and mangroves contribute to fish density coral and diversity on adjacent reefs. Mar Ecol Prog Ser 302:63-76 doi:10.3354/meps302063

Freeman AM (1991) Valuing environmental resources under alternative management regimes. Ecol Econ 3:247-256 doi:10.1016/ 0921-8009(91)90035-D

Gordon HS (1954) The economic theory of a common-property resource: the fishery. J Polit Econ 62:124-142 doi:10.1086/257497

Harborne AR, Mumby PJ et al (2006) The functional value of Caribbean coral reef, seagrass and mangrove habitats to ecosystem processes. Adv Mar Biol 50:59-159 doi:10.1016/S0065-2881(05)50002-6

Heal G (2000) Valuing ecosystem services. Ecosystems (N Y, Print) 3:24-30 doi:10.1007/s100210000006

Heal GM, Barbier EB et al (2005) Valuing ecosystem services: toward better environmental decision-making. The National Academies Press, Washington, D.C.

Homans FR, Wilen JE (1997) A model of regulated open access resource use. J Environ Econ Manage 32(1):1-21 doi:10.1006/jeem.1996.0947

Kareiva P, Watts S et al (2007) Domesticated nature: shaping landscapes and ecosystems for human welfare. Science 316 (5833):1866-1869 doi:10.1126/science. 1140170

Kremen C, Ostfeld RS (2005) A call to ecologists: measuring, analyzing, and managing ecosystem services. Front Ecol Environ 3(10):540-548
Lugo AE (2002) Can we manage tropical landscapes? An answer from the Caribbean perspective. Landscape Ecol 17:601-615 doi:10.1023/A:1021419815480

Lynne GD, Conroy P et al (1981) Economic value of marsh areas for marine production processes. J Environ Econ Manage 8:175-186 doi:10.1016/0095-0696(81)90006-1

Manson FJ, Loneragan NR et al (2005) A broad-scale analysis of links between coastal fisheries production and mangrove extent: a casestudy for northeastern Australia. Fish Res 74:69-95 doi:10.1016/j. fishres.2005.04.001

McCauley D (2006) Selling out on nature. Nature 443:27-28 doi:10.1038/443027a

Mumby P (2006) Connectivity of reef fish between mangroves and coral reefs: algorithms for the design of marine reserves at seascape scales. Biol Conserv 128:215-222 doi:10.1016/j.biocon.2005.09.042

Mumby PJ, Hastings A (2008) The impact of ecosystem connectivity on coral reef resilience. J Appl Ecol 45:854-862 doi:10.1111/j.13652664.2008.01459.x

Mumby PJ, Edwards AJ et al (2004) Mangroves enhance the biomass of coral reef fish communities in the Caribbean. Nature 427 (6974):533-536 doi:10.1038/nature02286

Nagelkerken I, Roberts CM et al (2002) How important are mangroves and seagrass beds for coral-reef fish? The nursery hypothesis tested on an island scale. Mar Ecol Prog Ser 244:299 305 doi:10.3354/meps244299

Newell R, Sanchirico JN et al (2005) Fishing quota markets. J Environ Econ Manage 49(3):437-462 doi:10.1016/j.jeem.2004.06.005

OECD (1997) Towards sustainable fisheries. Organization for Economic and Co-operation and Development, Paris

Ronnback P (1999) The ecological basis for economic value of seafood production supported by mangrove ecosystems. Ecol Econ 29:235-252 doi:10.1016/S0921-8009(99)00016-6

Sanchirico JN (2003) Managing marine capture fisheries with incentive based price instruments. Public Finance Manage 3(1):67-93

Sanchirico JN (2004) Designing a cost-effective marine reserve network: a bioeconomic metapopulation analysis. Mar Resour Econ 19(1):46-63

Sanchirico JN, Wilen JE (2001) A bioeconomic model of marine reserve creation. J Environ Econ Manage 42(3):257-276 doi:10.1006/ jeem.2000.1162

Sanchirico JN, Wilen JE (2002) The impacts of marine reserves on limited-entry fisheries. Nat Resour Model 15(3):380-400

Shinnaka T, Sano M et al (2007) Effects of mangrove deforestation on fish assemblage at Pak Phanang Bay, Southern Thailand. Fish Sci 73:862-870 doi:10.1111/j.1444-2906.2007.01407.x

Simpson SD, Meekan M et al (2005) Homeward sound. Science 308:221 doi:10.1126/science.1107406

Smith VL (1969) On models of commercial fishing. J Polit Econ 77:181-198 doi:10.1086/259507

Smith MD (2007) Generating value in habitat-dependent fisheries: the importance of fishery management institutions. Land Econ 83 (1):59-73

Swallow SK (1990) Depletion of the environmental basis for renewable resources: the economics of interdependent renewable and nonrenewable resources. J Environ Econ Manage 19(3):281296 doi:10.1016/0095-0696(90)90074-9

Tupper M (2007) Identification of nursery habitats for commercially valuable humphead wrasse Cheilinus undulatus and large groupers (Pisces: Serranidae) in Palau. Mar Ecol Prog Ser 332:189-199 doi:10.3354/meps332189

Valiela I, Bowen JL et al (2001) Mangrove forests: one of the world's threatened major tropical environments. Bioscience 51(10):807-815 doi:10.1641/0006-3568(2001)051[0807:MFOOTW]2.0.CO;2

Wilen JE (1985) Bioeconomics of renewable resource use. Handbook of Natural Resource and Energy Economics. A. V. Kneese and J. L. Sweeney. New York, Elsevier Science Publishers. 1:61-124 